\title{
An improved high performance liquid chromatography method for separation of lipophilic triterpenes from wunderlichia crulsiana followed by gas chromatography analysis
}

Cecilia Veronica Nuñez, ${ }^{a, b}$ Ernani Pinto, ${ }^{c, d}$ Pio Colepicolo, ${ }^{c}$ and Nidia Franca Roque ${ }^{b, e}$

${ }^{a}$ Instituto Nacional de Pesquisas da Amazônia, Coordenação de Pesquisas em Produtos Naturais, Av. André Araújo, 2936, Caixa Postal 478, CEP 69060-001, Aleixo, Manaus - AM, Brasil

${ }^{b}$ Instituto de Química, Departamento de Química Fundamental, Universidade de São Paulo, CP 26077, CEP 05599-970, São Paulo - SP, Brasil

'Instituto de Química, Departamento de Bioquímica, Universidade de São Paulo, CP 26077, CEP 05599-970, São Paulo - SP, Brasil

${ }^{d}$ Faculdade de Farmácia, Universidade de São Paulo, CP, CEP 05599-970, São Paulo - SP, Brasil

${ }^{e}$ Departamento de Química Orgânica, Instituto de Química, Universidade Federal da Bahia, Campus Universitário de Ondina, CEP 40170-290, Salvador - BA, Brasil

E-mail: cecilia@inpa.gov.br

Dedicated to Professor Otto Gottlieb on his $85^{\text {th }}$ birthday

(received 03 Feb 04; accepted 31 July 04; published on the web 02 Aug 04)

\begin{abstract}
A reverse-phase high performance liquid chromatographic (RP-HPLC) method was developed for the separation of lipophilic triterpenes found in Wunderlichia crulsiana. Three triterpenic fractions were obtained when stems extract was submitted to chromatography on silica gel; (1) triterpenes esterified with fatty acids, (2) triterpenes esterified with acetic acid and (3) free triterpenols. Fraction 2 was separated by RP-HPLC, using either methanol or acetonitrile as the mobile phase, yielding 13 identified triterpenes. Fraction 3 and 1, after hydrolysis, were acetylated, and compared by gas chromatography with the triterpenes isolated from fraction 2, allowing their identification.
\end{abstract}

Keywords: HPLC separation, lipophilic triterpenes GC analysis, Wunderlichia crulsiana, Asteraceae 


\section{Introduction}

The genus Wunderlichia Riedel ex Benth. belongs to the tribe Mutisieae, of the Asteraceae family, which is endemic to the Northwest of Brazil. ${ }^{1}$ This genus contains six species described, of which just W. mirabilis has been studied chemically; sesquiterpene lactones, triterpenes and polyacetylene were found. ${ }^{2}$ In this paper we deal with $W$. crulsiana Taulb. which grows in rocky places of Bahia, Goiás, São Paulo and Rio de Janeiro States. Only a chemical study has been done and flavonoids were isolated. ${ }^{3}$

Triterpenes are natural products widespread in nature, found from bacteria to humans. They play an important role as membrane stabilizers in plants ${ }^{4}$ and can act as anti-inflammatory, ${ }^{5}$ skin cancer chemo preventive, ${ }^{6}$ antiulcer ${ }^{7}$ and anti-HIV ${ }^{8}$ agents in humans.

Triterpene mixtures are very difficult to separate and isolate due to similarities in chemical structure. Pentacyclic triterpenes, for example, can differ only in double bond positions and/or methyl groups. ${ }^{9}$ It is possible to achieve a fraction that contains solely triterpenes with classic chromatographic columns. However, only high resolution chromatography procedures, such as HPLC, can separate these compounds. Few HPLC methods have been developed for this purpose. $^{10}$

This paper describes a reverse-phase (RP-HPLC) method for the isolation of acetate triterpenes and 3-oxo triterpenes followed by gas chromatography (GC) analysis of these compounds from W. crulsiana.

\section{Results and Discussion}

A preliminary chemical investigation of stems of $W$. crulsiana showed that the dichloromethane extract is rich in triterpene mixture, mainly triterpenes esterified with acetate and fatty acids and sesquiterpene lactones, which were described elsewhere. ${ }^{11}$

Figure 1 shows the fractionation of the dichloromethane extract of stems of $W$. crulsiana. The first three fractions obtained from the chromatographic column were identified by ${ }^{1} \mathrm{H}$ NMR as triterpenes esterified with fatty acids (fraction 1), triterpenes esterified with acetic acid (fraction 2) and hydroxy triterpenes (fraction 3). Fraction 2 and 3 were analyzed by GC and fraction 2 showed the highest complexity, which was separated by HPLC. Since the $\lambda_{\max }$ of this fraction was at $201 \mathrm{~nm}$ we decided to use RP-HPLC because the solvents employed did not interfere with the detection method. Various C18-HPLC analytical columns and conditions were tested and Luna (Phenomenex ${ }^{\circledR}$ ) showed the best chromatogram resolution (Fig. 2), with an isocratic mobile phase. The chromatogram showed at least nine well separated peaks, which were collected using a semi-preparative column (Luna, Phenomenex ${ }^{\circledR}$ ). Mixtures of triterpenes were identified using the methodology described by Gallegos and Roque ${ }^{12}$ which allowed to analyze the ${ }^{13} \mathrm{C}$-NMR data of each triterpene. The identification of pure triterpenes was carried out by comparison with the ${ }^{13} \mathrm{C}-\mathrm{NMR}$ data reported in the literature. ${ }^{9}$ 
Table 1 shows the identified triterpenes, their concentration and their GC retention times. Figure 3 shows the chemical structure of the triterpenes identified.

Fractions F2.6 and F2.8 containing the two minor compounds not identified were mixed and separated by HPLC (mobile phase: ACN) (Fig. 1). This procedure led to the identification of fern-8-en-3-one and $\beta$-amirinyl acetate.

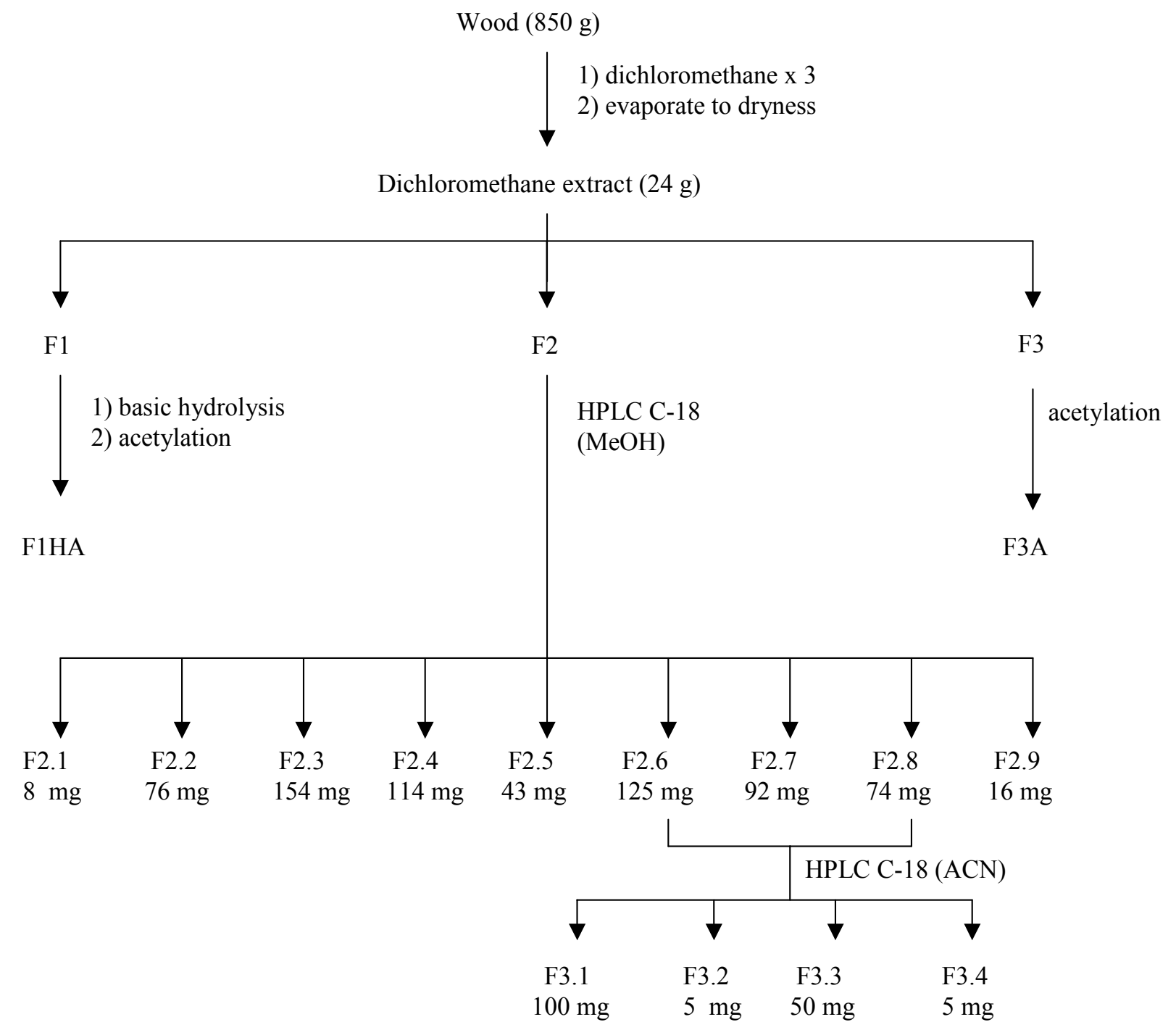

Figure 1. Dichloromethane extract fractionation of Wunderlichia crulsiana stems. 


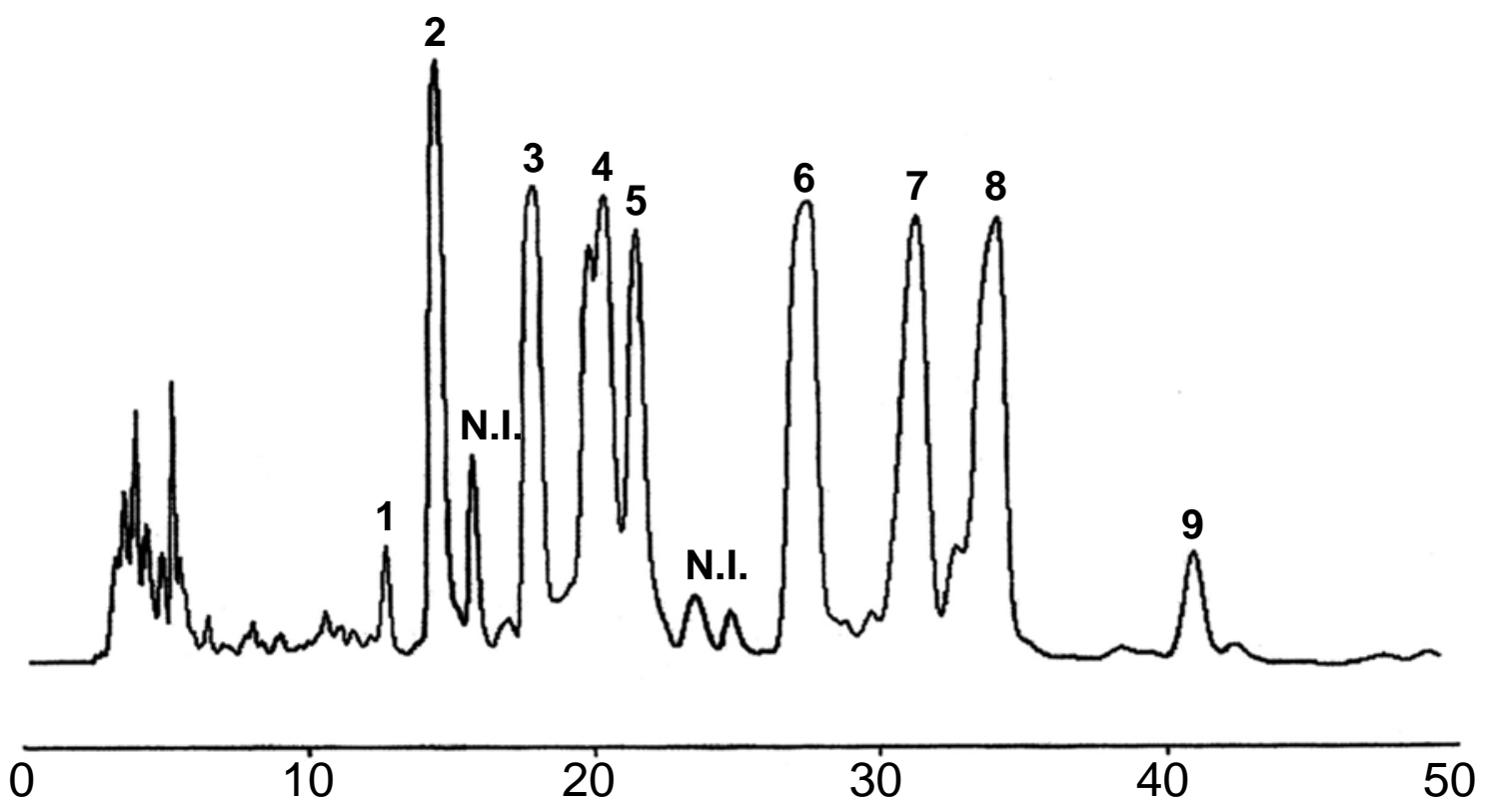

Figure 2. HPLC chromatogram (UV detection at $201 \mathrm{~nm}$ ) of fraction 2. (For chromatographic protocol see Experimental section). 
Table 1. Fractions obtained by HPLC, showing weight, purity and GC retention time of identified triterpenes from Wunderlichia crulsiana

\begin{tabular}{|c|c|c|c|c|c|c|}
\hline Fraction & Mass (mg) & $\mathrm{RT}(\min )$ & $\mathrm{k}^{\prime}$ & $\mathrm{SD}(\mathrm{n}=4)$ & $\%$ & Identified substance \\
\hline $\mathrm{F} 2.1$ & 8 & 9.79 & 4.82 & 0.29 & 100 & dammara-20,24-dien-3-one 1 \\
\hline F2.2 & 76 & 11.09 & 5.60 & 0.07 & 100 & lupen-3-one 2 \\
\hline \multirow[t]{2}{*}{$\mathrm{F} 2.3$} & 154 & 10.40 & 5.33 & 0.23 & 3 & not identified \\
\hline & & 11.08 & 5.56 & 0.10 & 97 & lupen-3-one 2 \\
\hline \multirow[t]{4}{*}{$\mathrm{F} 2.4$} & 114 & 10.28 & 5.01 & 0.13 & 49 & $\beta$-amirin-3-one 3 \\
\hline & & 10.40 & 5.14 & 0.07 & 24 & germanic-3-one 4 \\
\hline & & 12.78 & 6.21 & 0.12 & 18 & pseudotaraxaster-3-one 5 \\
\hline & & 13.03 & 6.33 & 0.10 & 8 & taraxaster-3-one 6 \\
\hline \multirow[t]{3}{*}{$\mathrm{F} 2.5$} & 43 & 11.05 & 5.59 & 0.11 & 6 & lupen-3-one 2 \\
\hline & & 12.05 & 6.11 & 0.16 & 3 & not identified \\
\hline & & 12.77 & 6.34 & 0.07 & 91 & pseudotaraxaster- 3 -one 5 \\
\hline \multirow[t]{2}{*}{ F2.6 } & 125 & 11.94 & 5.83 & 0.19 & 7 & fern-8-en-3-one 11 \\
\hline & & 13.37 & 6.50 & 0.18 & 93 & lupenyl acetate 10 \\
\hline \multirow[t]{2}{*}{ F2.7 } & 92 & 12.41 & 6.23 & 0.15 & 72 & $\beta$-amirin acetate 7 \\
\hline & & 15.80 & 7.75 & 0.12 & 22 & taraxasteryl acetate 8 \\
\hline \multirow[t]{2}{*}{ F2.8 } & 74 & 13.34 & 6.63 & 0.15 & 9 & $\alpha$-amirin acetate 13 \\
\hline & & 15.51 & 7.71 & 0.09 & 91 & pseudotaraxasteryl acetate 12 \\
\hline F2.9 & 16 & 14.46 & 7.12 & 0.16 & 100 & fern- 8 -en- $3 \beta$-yl acetate 9 \\
\hline \multirow[t]{2}{*}{ F3.1 } & 100 & 11.92 & 6.05 & 0.06 & 3 & fern-8-en-3-one 11 \\
\hline & & 13.38 & 6.78 & 0.04 & 97 & lupenyl acetate 10 \\
\hline \multirow{2}{*}{ F3.2 } & 5 & 12.00 & 6.05 & 0.03 & 55 & fern-8-en-3-one 11 \\
\hline & & 13.42 & 6.65 & 0.08 & 45 & lupenyl acetate 10 \\
\hline \multirow[t]{2}{*}{ F 3.3} & 50 & 12.39 & 6.10 & 0.10 & 6 & $\beta$-amirin acetate 7 \\
\hline & & 15.49 & 7.67 & 0.15 & 94 & pseudotaraxasteryl acetate 12 \\
\hline F3.4 & 5 & 13.33 & 6.51 & 0.24 & 100 & $\alpha$-amirin acetate 13 \\
\hline \multirow[t]{7}{*}{ F1HA } & 1300 & 7.520 & 3.63 & 0.08 & 7 & not identified \\
\hline & & 12.582 & 6.08 & 0.08 & 20 & $\beta$-amirin acetate 7 \\
\hline & & 12.716 & 6.17 & 0.10 & 11 & pseudotaraxaster-3-one 5 \\
\hline & & 13.666 & 6.58 & 0.20 & 42 & lupenyl acetate 10 \\
\hline & & 14.593 & 7.04 & 0.21 & 4 & fern- 8 -en- $3 \beta$-yl acetate 9 \\
\hline & & 15.654 & 7.59 & 0.18 & 9 & pseudotaraxasteryl acetate 12 \\
\hline & & 15.890 & 7.71 & 0.12 & 2 & taraxasteryl acetate 8 \\
\hline \multirow[t]{3}{*}{$\mathrm{F} 3 \mathrm{~A}$} & 1000 & 12.415 & 6.22 & 0.01 & 55 & $\beta$-amirin acetate 7 \\
\hline & & 13.598 & 6.80 & 0.02 & 30 & lupenyl acetate 10 \\
\hline & & 15.524 & 7.77 & 0.01 & 15 & pseudotaraxasteryl acetate 12 \\
\hline
\end{tabular}



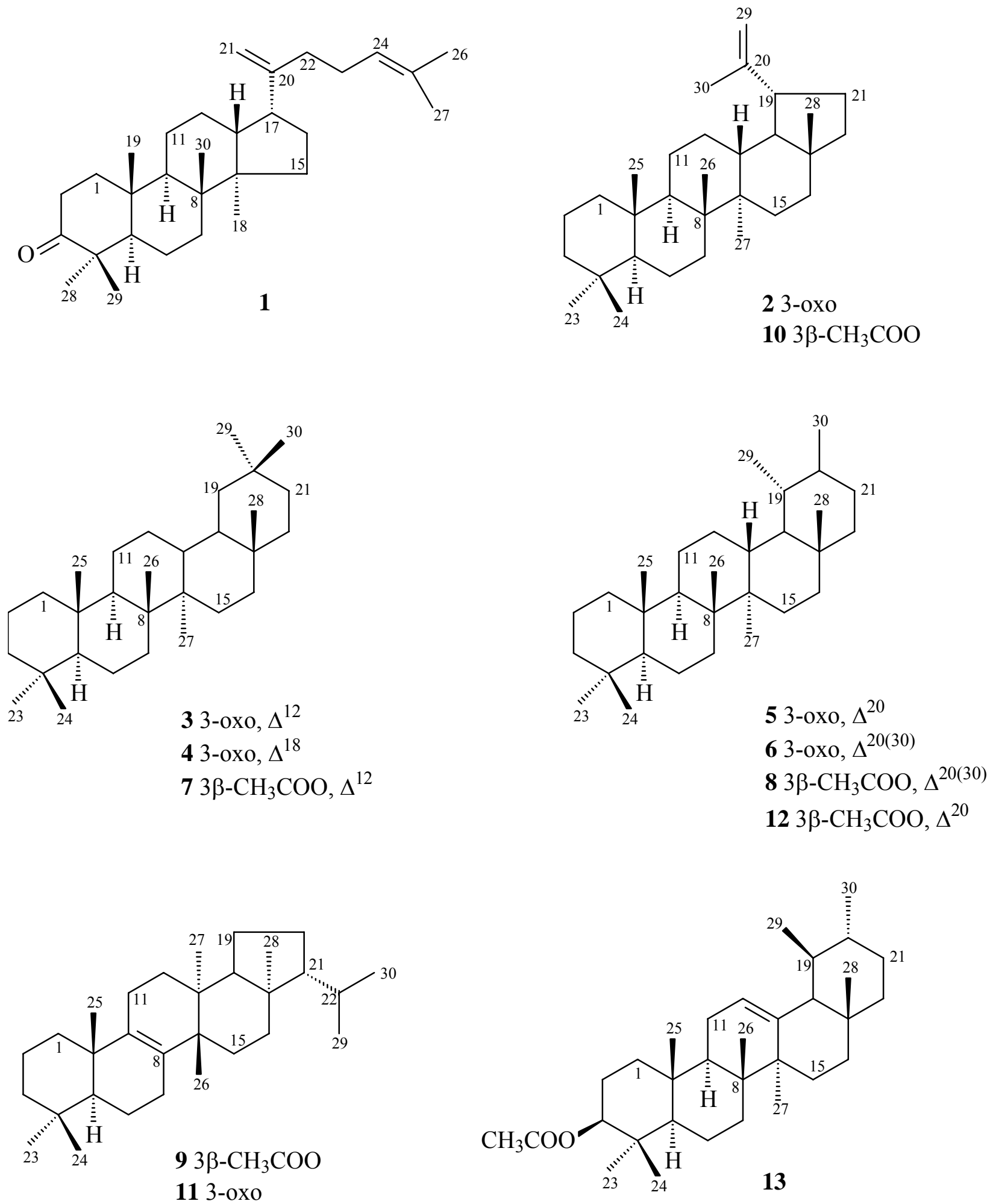

Figure 3. Identified triterpenes from Wunderlichia crulsiana. 


\section{Conclusions}

This methodology with isocratic HPLC condition is useful to separate lipophilic triterpenes and can be a sensitive tool to follow triterpenes biosynthesis or quantify these compounds in other plant extracts. Also, with the isolated standards, it is possible to identify triterpenes from other sources by GC analysis.

To know the kind of triterpenes present in the fraction 1 and 3, the fraction 1 was hydrolyzed and then acetylated and fraction 3 was acetylated. Then, both fractions were analyzed by GC, using the triterpenes isolated or in mixture well known as standard.

\section{Experimental Section}

Material. All solvents used for chromatographic purposes were HPLC grade. Other solvents were ACS grade or equivalent.

Plant material. The plant material was collected in Morro do Pai Inácio (S 12 $27^{\prime} 326^{\prime \prime}$ and W $41^{\circ} 28^{\prime}$ 509'"), Chapada Diamantina, Bahia State, Brazil, in September 19, 1998. The identification of plant material was made by Prof. Dr. M. L. Guedes (Instituto de Botânica Universidade Federal da Bahia) and by Prof. Dr. J. Pirani (Instituto de Botânica - Universidade de São Paulo). Voucher specimens are deposited in SPF Herbarium of Instituto de Botânica da Universidade de São Paulo under collector's number: Nunez C.V.-004.

Extraction of triterpenes. Dried powdered stems were extracted with dichloromethane. The dichloromethane extract $(24 \mathrm{~g})$ was submitted to column chromatography on silica gel 60 (Merck, Darmstadt, Germany) using n-hexane/dichloromethane 1:1 (fractions 1 and 2), nhexane/dichloromethane 2:8 (fraction 3) as mobile phase.

Thin layer chromatography. The TLC system employed in this study was silica $\mathrm{GF}_{254}$ plates (Aldrich, Wisconsin, USA) with dichloromethane as mobile phase and ceric sulfate: sulfuric acid $(1: 1,2 \mathrm{w} / \mathrm{w})$ as visualizing agent.

High performance liquid chromatography. HPLC was performed using a Shimadzu system consisting of a SPD-10AV UV detector, SPD-M10AV diode array detector and CBM 10A Communications Bus Module. HPLC columns were Luna C-18 Phenomenex ( 250 x $4.6 \mathrm{~mm}$ i.d. and $250 \times 10.0 \mathrm{~mm}$, both with $5 \mu \mathrm{m}$ particle diameter). In order to protect the integrity of the analytical and semi-preparative column, all analyses were performed with a coupled C-18 guard column ( $4 \times 3 \mathrm{~mm}, 5 \mu \mathrm{m}$ particle diameter). The first fractionation was made using methanol $(\mathrm{MeOH})$ as the mobile phase at a flow rate of $4.7 \mathrm{~mL} / \mathrm{min}$ and the samples were monitored at $201 \mathrm{~nm}$. The second fractionation was made using acetonitrile as the mobile phase at the same flow rate and monitored at $210 \mathrm{~nm}$. To dissolve the samples a mixture of iso-propanol:MeOH 1:1 was used.

Gas chromatography. The triterpenes isolated by HPLC were analyzed by GC. The GC analyses were performed using a Hewlett Packard 5890 series II GC, HP 7673 automatic injector 
and HP 3396A integrator, a 30 m capillary column (5\% phenyl in 95\% methyl-silicon), Helium as carrier gas and an FID detector. The oven temperature was $290{ }^{0} \mathrm{C}$, injector temperature $280{ }^{\circ} \mathrm{C}$ and detector temperature $310{ }^{\circ} \mathrm{C}$.

NMR spectroscopy. NMR spectra were recorded at $125 \mathrm{MHz}$ for ${ }^{13} \mathrm{C}$ and $500 \mathrm{MHz}$ for ${ }^{1} \mathrm{H}$ (Bruker DRX-500) using $\mathrm{CDCl}_{3}$ (Aldrich) as solvent and internal standard.

Reaction conditions. The fraction containing triterpenes esterified with fatty acids (fraction 1) was hydrolyzed using $\mathrm{KOH}$ and $\mathrm{MeOH}$, in the proportion of $1 \mathrm{~g}$ of sample, $1 \mathrm{~g}$ of $\mathrm{KOH}$ and $125 \mathrm{~mL}$ of $\mathrm{MeOH}$. The reaction time was 1 hour under reflux. The solution was then concentrated to $100 \mathrm{~mL}$ under vacuum and the final volume was adjusted with distilled $\mathrm{H}_{2} \mathrm{O}$. The aqueous $\mathrm{MeOH}$ was partitioned against diethyl ether $(5 \times 200 \mathrm{~mL})$. The diethyl ether solution was concentrated under vacuum to $100 \mathrm{~mL}$ and partitioned against $0.1 \mathrm{M} \mathrm{KOH}(1 \mathrm{x} 100 \mathrm{~mL})$ and distillated $\mathrm{H}_{2} \mathrm{O}(2 \times 100 \mathrm{~mL})$. The diethyl ether phase was dried with $\mathrm{Na}_{2} \mathrm{SO}_{4}$, filtered and concentrated.

Since the standards were triterpenes esterified with acetic acid, the fraction hydrolyzed above and the fraction which contained the free triterpenols (fraction 3) were acetylated using acetic anhydride and pyridine, the proportion being $1 \mathrm{~mL}$ of acetic anhydride and $1 \mathrm{~mL}$ of pyridine for $20 \mathrm{mg}$ of sample. The solution was heated for 24 hours at $60{ }^{\circ} \mathrm{C}$. The solution was rinsed with distilled $\mathrm{H}_{2} \mathrm{O}$, and diethyl ether was added to extract the acetylated compounds.

\section{Acknowledgments}

The authors thank FAPESP for financial support and for the fellowships to CVN and EP, also Prof. Dr. J. Pirani and Prof. Dr. M. L. Guedes for the identification of plant material.

\section{References}

1. Stannard, B. L.; Harvey, Y. B.; Harley, R. M. Flora of the Pico das Almas, Chapada Diamantina - Bahia, Brazil; Royal Botanic Gardens: Kew, 1995.

2. Vichnewski, W.; Herz W.; Kumar N. J. Org. Chem. 1979, 44, 2575. Bohlmann, F.; Zdero, C.; Robinson, H.; King, R.M. Phytochemistry 1981, 20, 1631. Bohlmann, F.; Ludwig, G.W.; Jakupovic, J.; King, R. M.; Robinson, H. Liebigs Ann. Chem. 1984, 228.

3. André, A. C. G. M.; Dias D. A.; Vichnewski W. Biochem. Syst. Ecol. 2002, 30, 483.

4. Havaux, M. Trends Plant Sci. 1998, 3, 147.

5. Safayhi, H.; Sailer, E. R. Planta Med. 1997, 63, 487. Akihisa, T.; Yasukawa, K.; Kimura, Y.; Takase, S.; Yamanouchi, S.; Tamura, T. Chem. Pharm. Bull. 1997, 45, 2016.

6. Saleem, M.; Alam, A.; Arifin, S.; Shah, M. S.; Ahmed, B.; Sultana, S. Pharm. Res. 2001, 43, 127. 
7. Queiroga, C. L.; Silva, G. F.; Dias, P. C.; Possenti, A.; Carvalho, J. E. J. Ethnopharmacol. 2000, 72, 465.

8. Holz-Smith, S. L.; Sun, I. C.; Jin, L.; Matthews, T. J.; Lee, K. H.; Chen, C. H. Antimicrob. Agents Chemother. 2001, 45, 60.

9. Mahato, S. B.; Kundu, P. Phytochemistry 1994, 37, 1517.

10. Gunther, B.; Wagner, H. Phytomedicine 1996, 3, 59.

11. Nunez, C. V.; Zacheu, F.; Pinto, E.; Roque, N. F.; Colepicolo, P.; Brigagão, M. R. P. L. Life Sci. 2003, 73, 17, 2161.

12. Olea, R. S. G.; Roque, N. F. Quim. Nova 1990, 13, 278. 